\title{
COMMENTARY
}

\section{C-reactive protein in community-acquired sepsis: you can teach new tricks to an old dog}

\author{
Jorge IF Salluh ${ }^{* 1,2}$ and Thiago Lisboa ${ }^{3,4}$ \\ See related research by Póvoa et al., http://ccforum.com/content/15/4/R169
}

\begin{abstract}
Severe sepsis is a major challenge for clinicians caring for acutely ill patients. For many years, several biomarkers have been tested and proposed to improve the ability not only to diagnose but also to anticipate clinical response to antibiotics. Despite the availability of many sophisticated and novel biomarkers, current evidence demonstrates that C-reactive protein (CRP), a well-known and relatively inexpensive biomarker, is useful in the clinical setting. The sequential evaluation of plasma CRP concentrations in patients with severe sepsis and the interpretation of its patterns may allow assessments of individual prognosis and response to treatment.
\end{abstract}

Assessment of clinical resolution criteria and response to treatment in sepsis is a complex and unresolved issue. The intricate pathophysiology limits our ability to anticipate outcomes and to effectively use tools to improve the decision-making process in sepsis. In the previous issue of Critical Care, Póvoa and colleagues [1] provide us clinically relevant data on how we can obtain the best information when using a biomarker to assess clinical response and identify relevant evolution patterns in septic patients.

This large observational multicenter study evaluated serial C-reactive protein (CRP) measurements to describe the clinical course of community-acquired sepsis in patients admitted to the ICU. Instead of using a traditional approach for biomarker evaluation (that is, analyzing mean differences of absolute values), the authors performed a complex analysis of serial measurements of CRP within 5 days of ICU admission. As early as

*Correspondence: jorgesalluh@gmail.com

'D'Or Institute for Research and Education, Rua Diniz Cordeiro, 30. Botafogo, Rio de Janeiro, 22281-100, Brazil

Full list of author information is available at the end of the article day 3, a clinical response pattern was identified as a function of CRP variation and was assessed as the ratio between CRP value on each day and the baseline CRP. This approach of dynamic evaluation using the CRP ratio was used in different studies involving patients with ventilator-associated pneumonia (VAP) to assess an association between CRP variation and appropriateness of antibiotic therapy [2,3]. Although CRP is frequently criticized because of its relative unspecific increases occurring as a result of several non-infectious inflammatory stimuli, CRP values usually present a sharp decrease after the withdrawal of the inflammatory injury [4]. Therefore, when the patient is his or her own control (that is, a relative variation in the same patient is considered a marker for clinical response), we may control for the potential differences secondary to different baseline inflammation response level and assess the variation occurring according to the actual resolution of infectious stimulus.

In the original study evaluating clinical response assessment with the CRP patterns in VAP, Póvoa and colleagues [2] classified patients as having a fast response, a slow response, or no response. In the present study, the authors used a large multicenter prospective cohort to validate the same concept in community-acquired sepsis and objectively defined the response patterns as a function of CRP ratio after 5 days of antibiotic therapy. This classification was associated with clinical outcomes such as ICU mortality and resolution of organ dysfunction as assessed by the Sequential Organ Failure Assessment (SOFA) score. Additionally, the in-hospital mortality was significantly associated with the individual pattern of response.

The main biologic explanations for these findings are related to the fact that CRP is a prototypical marker of acute-phase response which is correlated with bacterial burden [5]. Lisboa and colleagues [3] demonstrated that a CRP level decrease correlates with the decreases found in bacterial load in respiratory samples in patients with VAP. Therefore, it has been proposed that CRP could be used in critically ill patients as a surrogate of both clinical response to antibiotics and reduction in bacterial load. 
Although CRP has been around for a long time, the enthusiasm for its clinical use in sepsis has waned in the last decade. This may be ascribed to the fact that baseline CRP concentrations lack specificity in terms of the etiologic distinction between bacterial and non-infectious inflammatory insults and also the limited role in outcome prediction. However, CRP has several other useful characteristics that are not fully acknowledged but that make this biomarker more appealing to use in the clinical setting, especially for critically ill patients. Recent studies have demonstrated that the time course of CRP seems to be relatively unaffected by the use of systemic corticosteroids [6]. Additionally, even when significant immunosupression is present (such as in critically ill cancer patients with neutropenic sepsis), CRP concentrations are largely unaffected [7]. The only subset of patients in whom CRP response seems to be blunted consists of patients with severe hepatic dysfunction [8]. Other interesting biologic features for its use in severely ill patients, as opposed to the use of procalcitonin, seem to be related to the fact that CRP is not influenced by renal dysfunction and does not express a fatigue phenomena, even in the case of patients with recurrent infections, and several other limitations are also associated with the use of this more 'novel' biomarker [912]. This is at least partially explained by the fact that its CRP synthesis will occur after systemic inflammatory stimulus. Interestingly, CRP does not present a major noise-to-signal ratio issue [10]. Accordingly, resolution of inflammation will lead to a cessation or decreased rate of synthesis, resulting in a fast decline in plasma concentrations. Recently, a randomized clinical trial evaluating a procalcitonin-guided intervention to increase early appropriate antibiotics failed to improve survival in septic patients admitted to the ICU and pointed to possible flaws in the immediate use of this biomarker in the clinical setting [13].

Given all of these facts, why is CRP not routinely employed as a marker of clinical resolution? What are the flaws and potential concerns impeding its widespread clinical implementation? First of all, until the study by Póvoa and colleagues [1], most published data were from single-center studies involving a small to moderate number of patients. In addition, there are no studies evaluating CRP-guided antimicrobial therapy in patients with severe sepsis. In order to implement theragnostics [14] as a way to improve the care of patients with severe sepsis, studies [15] are now being conducted and others to be performed with this purpose are expected to shed more light on these most relevant questions.

\footnotetext{
Abbreviations

CRP, C-reactive protein; ICU, intensive care unit; VAP, ventilator-associated pneumonia.
}

\section{Competing interests}

The authors declare that they have no competing interests.

\section{Author details}

'D'Or Institute for Research and Education, Rua Diniz Cordeiro, 30. Botafogo, Rio de Janeiro, 22281-100, Brazil. ²Postgraduate Program, Instituto Nacional de Câncer, Praca Cruz Vermelha, 23-10 Andar, Rio de Janeiro, 20230-130, Brazil. ${ }^{3}$ Critical Care Department, Hospital de Clínicas do Porto Alegre, Universidade Federal do Rio Grande do Sul, Rua Ramiro Barcelos 2350, Rio Branco, Porto Alegre, 90035-003, Brazil. ${ }^{4}$ Intensive Care Unit, Hospital Santa Rita, Rede Institucional de Pesquisa e Inovação em Medicina Intensiva (RIPIMI), Complexo Hospitalar Santa Casa, Pc D Feliciano, 135 - Centro, Porto Alegre, 90020-160, Brazil.

Published: 7 September 2011

\section{References}

1. Póvoa P, MD, Teixeira-Pinto A, Carneiro AH and the Portuguese CommunityAcquired Sepsis Study Group (SACiUCI): C-reactive protein, an early marker of community-acquired sepsis resolution: a multi-center prospective observational study. Crit Care 2011, 15:R169.

2. Póvoa P, Coelho L, Almeida E, Fernandes A, Mealha R, Moreira P, Sabino H: C-Reactive protein as a marker of ventilator associated pneumonia resolution - a pilot study. Eur Respir J 2005, 25:804-812.

3. Lisboa T, Seligman R, Diaz E, Rodriguez A, Teixeira PJ, Rello J: C-reactive protein correlates with bacterial load and appropriate antibiotic therapy in suspected ventilator-associated pneumonia. Crit Care Med 2008, 36:166-171.

4. Pepys MB, Baltz ML: Acute phase proteins with special reference to C-reactive protein and related proteins (pentaxins) and serum amyloid $\mathrm{A}$ protein. Adv Immunol 1983, 34:141-212.

5. Peters RP, de Boer RF, Schuurman T, Gierveld S, Kooistra-Smid M, van Agtmael MA, Vandenbroucke-Grauls CM, Persoons MC, Savelkoul PH: Streptococcus pneumoniae DNA load in blood as a marker of infection in patients with community-acquired pneumonia. J Clin Microbiol 2009, 47:3308-3312.

6. Salluh Jl, Soares M, Coelho LM, Bozza FA, Verdeal JC, Castro-Faria-Neto HC, e Silva JR, Bozza PT, Póvoa P: Impact of systemic corticosteroids on the clinical course and outcomes of patients with severe community-acquired pneumonia: a cohort study. J Crit Care 2011, 26:193-200.

7. Povoa P, Souza-Dantas VC, Soares M, Salluh Jl: C-reactive protein in critically ill cancer patients with sepsis: influence of neutropenia. Crit Care 2011, 15:R129.

8. Silvestre JP, Coelho LM, Póvoa P: Impact of fulminant hepatic failure in C-reactive protein? J Crit Care 2010, 25:657 e7-e12.

9. Dahaba AA, Rehak PH, List WF: Procalcitonin and C-reactive protein plasma concentrations in nonseptic uremic patients undergoing hemodialysis. Intensive Care Med 2003, 29:579-583.

10. Povoa P: Serum markers in community-acquired pneumonia and ventilator-associated pneumonia. Curr Opin Infect Dis 2008, 21:157.

11. Becker KL, Snider R, Nylen ES: Procalcitonin assay in systemic inflammation, infection, and sepsis: clinical utility and limitations. Crit Care Med 2008, 36:941-952.

12. Ho KM, Lipman J: An update on C-reactive protein for intensivists. Anaesth Intensive Care 2009, 37:234-241.

13. Jensen JU, Hein L, Lundgren B, Bestle MH, Mohr TT, Andersen MH, Thornberg KJ, Løken J, Steensen M, Fox Z, Tousi H, Søe-Jensen P, Lauritsen AO, Strange D, Petersen PL, Reiter N, Hestad S, Thormar K, Fjeldborg P, Larsen KM, Drenck NE, Ostergaard C, Kjær J, Grarup J, Lundgren JD; for the Procalcitonin And Survival Study (PASS) Study Group: Procalcitonin-guided interventions against infections to increase early appropriate antibiotics and improve survival in the intensive care unit: a randomized trial. Crit Care Med 2011 May 12. [Epub ahead of print].

14. Angus DC, Mira JP, Vincent JL: Improving clinical trials in the critically ill. Crit Care Med 2010, 38:527-532.

15. Use of Inflammatory Biomarkers to Guide Antibiotic Therapy in Patients With Severe Infections [http://www.clinicaltrials.gov/ct2/show/NCT0093401 1?term $=$ CRP + AND+sepsis\&rank=1].

\section{doi:10.1186/cc10301}

Cite this article as: Salluh JIF, Lisboa T: C-reactive protein in communityacquired sepsis: you can teach new tricks to an old dog. Critical Care 2011, 15:186. 